\title{
Direct Observation of Molten Steel Meniscus in \\ CC Mold during Casting*
}

\author{
By Akira MATSUSHITA,** Katsuyuki ISOGAMI,** Masami TEMMA,** \\ Takeyoshi NINOMIYA** and Kazuhiko TSUTSUMI***
}

\begin{abstract}
Synopsis
Free surface fluctuations of molten steel in the mold of a continuous caster are considered to have a significant effect on the surface quality of the cast.

To find out the relationship between the surface wave motion of molten steel near the mold wall during casting and mold oscillation, the meniscus of molten steel in the mold was directly observed through a quartz glass window mounted on the mold wall. As a result, it was confirmed that the meniscus fluctuates at the same period and phase as those of the mold oscillation.
\end{abstract}

Key words: continuous casting; meniscus; quality; mold.

\section{Introduction}

Stabilization of the surface quality of continuously cast at a high level is important for the improvement of product qualities. Further attention is being paid to the importance for stabilization of the surface quality of casts, as more and more continuous casting and rolling process are being directly coupled for direct rolling. Since free surface fluctuations of molten steel in the mold are considered to have a significant effect on the surface quality of cast, many researches have been done on the condition of mold oscillation, powder properties, etc. In these researches, it is generally assumed that the meniscus slides along the mold wall and that it is stationary when it is viewed from the stationary surface. On these assumptions, a study was once made to reduce the flow rate of molten steel discharged from the nozzle by the electromagnetic force as a means to restrain free surface fluctuations of molten steel. ${ }^{1)}$ The other reports suggested that the meniscus is not stationary. ${ }^{2,3)}$ The dynamic behavior of free surface fluctuations of molten steel in the mold during casting is a field which has yet to be explored.

To find out the relationship between the surface wave motion of molten steel near the mold wall during casting and mold oscillation, the meniscus of molten steel in the mold was directly observed through a quartz glass window mounted on the mold wall. This paper presents a summary of the results mentioned above.

\section{Method of Direct Observation of Meniscus}

The apparatus used for direct observation of the meniscus is schematically shown in Fig. 1.

A quartz glass window was mounted on the mold at the position of the meniscus of molten steel. Imagefiber (50 000 picture elements, $50 \mathrm{~mm}$ field of vision) was fitted to the back of the window, through which the meniscus was observed directly. Images of the meniscus obtained by the image-fiber were recorded by the use of a tape recorder. Amplitude of mold oscillation was measured by a differential transformer and recorded by a tape recorder.

The casting conditions adopted for the experiment are shown in Table 1.

\section{Results of Experiment}

\section{Observed Images of Meniscus}

An example of the meniscus observed is shown in Fig. 2. Figure 3 shows an explanatory drawing of Fig. 2. In the experiment, the glass window was mounted in the corner of the mold. Hence, about a half of the screen represents the narrow face of mold. When the bath level of mold is set so as to be in the glass field of vision, a curved, bright portion moving up and down in synchronization with mold oscillation can be observed near the narrow face of mold. This bright portion represents the molten steel, and

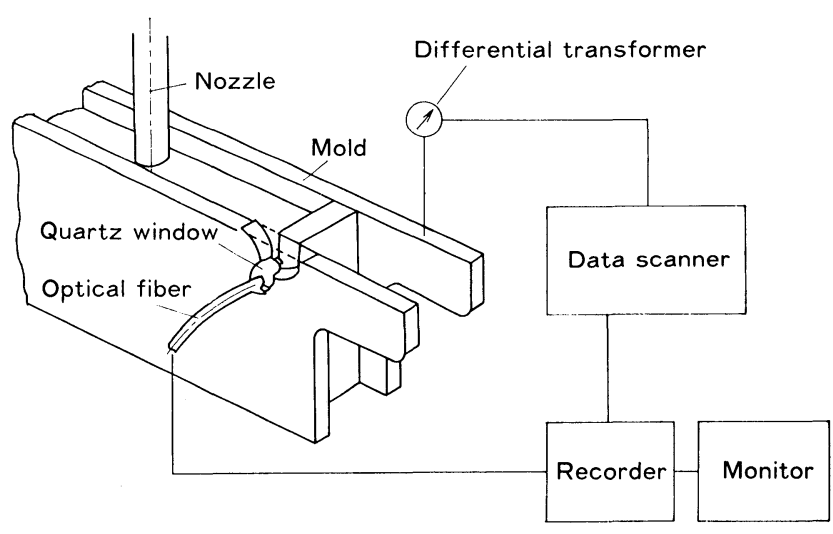

Fig. 1. Apparatus used for experiment.

Table 1. Casting condition.

$\begin{array}{ll}\text { Casting speed } & 0.53 \sim 1.60(\mathrm{~m} / \mathrm{min}) \\ \text { Mold oscillation cycle } & 1.14 \sim 2.11(\mathrm{~Hz}) \\ \text { Oscillation amplitude } & \pm 6(\mathrm{~mm})(\text { approximate } \\ \text { Mold size } & 920 \times 250(\mathrm{~mm}) \\ \text { Mold taper } & 1.37(\% / \mathrm{m}) \\ \text { Steel grade } & \mathrm{L}[\mathrm{c}]-\mathrm{Al}-\mathrm{killed} \text { steel }\end{array}$

\footnotetext{
* Presented to the 113th ISIJ Meeting, April 1987, S200, at The University of Tokyo in Tokyo. Manuscript received on August 17, 1987; accepted in the final form on January 14, 1988. (C) 1988 ISIJ

** Sakai Works, Nippon Steel Corporation, Chikko Yawata-cho, Sakai 590.

*** Head Office, Nippon Steel Corporation, Otemachi, Chiyoda-ku, Tokyo 100.
} 


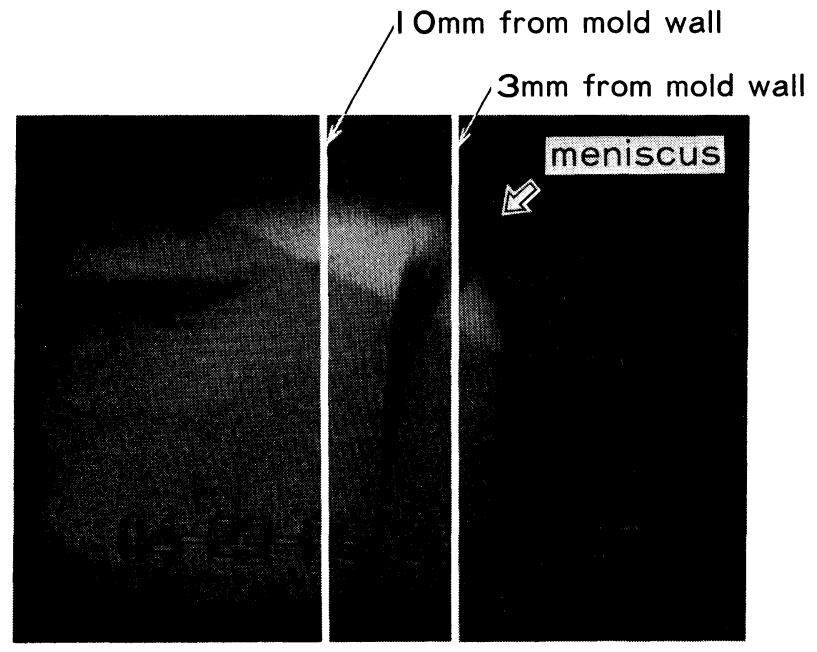

Fig. 2. Example of meniscus observation.

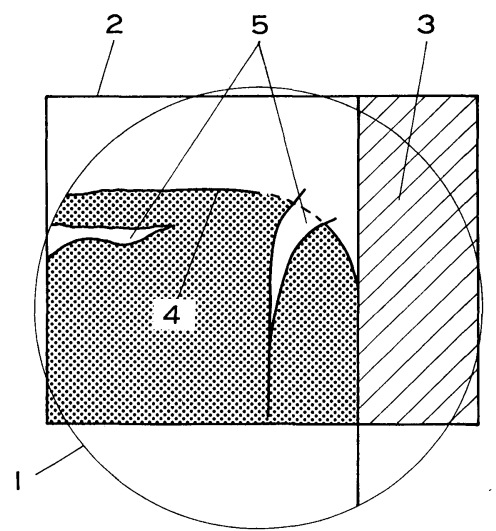
$\begin{array}{ll}\text { 1: Glass window field of } 3: \text { Mold narrow face } \\ \text { vision } & 4: \text { Meniscus }\end{array}$

2: Camera field of vision 5: Cracks

Fig. 3. Explanatory drawing of meniscus.

its upper edge is considered to be the meniscus. Strictly speaking, the meniscus is a three-dimensional curved surface having a curvature not only in the direction of the glass plane but also in the direction of the mold thickness. In this paper, however, the upper edge of the high-brightness portion of image is defined as the meniscus and the dynamic behavior of the upper edge is analyzed.

Since a powder was used in the experimental casting, it flowed into the clearance between the glass window and molten steel. Thus, the meniscus observed represents the image obtained through a film of the molten powder.

\section{Displacement of Meniscus}

The behavior of the meniscus at the casting speed of $0.53 \mathrm{~m} / \mathrm{min}$ is shown in Fig. 4 .

Figure 4 (a) shows the displacement of the mold. Figure 4(b) shows the displacement of the meniscus observed through the monitor view. Figure 4(c) shows the displacement of the meniscus from the stationary point obtained according to the mold displacement (Fig. 4(a)) and the displacement of the meniscus observed through the monitor view (Fig.

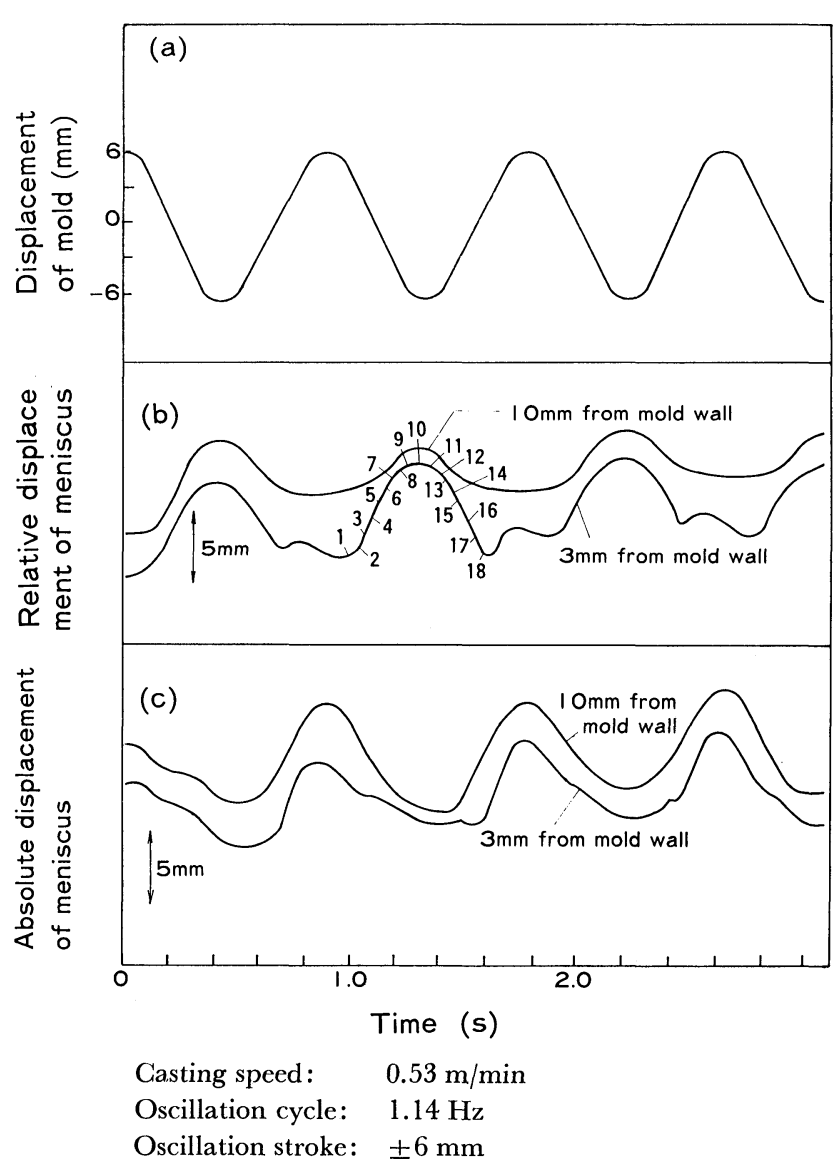

Fig. 4. Behavior of meniscus at the casting speed of $0.53 \mathrm{~m} / \mathrm{min}$.

4(b)) (hereinafter referred to as the absolute displacement of the meniscus). The patterns shown in Figs. 4(a) and (c) indicate that the meniscus fluctuates at the same period and phase as those of mold oscillation. Namely, the meniscus rises as the mold rises. similarly, the meniscus lowers as the mold lowers.

From these phenomena, it was found that the meniscus is not stationary, but fluctuates in synchronization with mold oscillation.

Fluctuations of meniscus at the casting speed of $1.60 \mathrm{~m} / \mathrm{min}$ are shown in Fig. 5 .

Figure 5 shows that the meniscus fluctuates at the same period and phase as those of mold oscillation.

The absolute fluctuations of meniscus at the casting speeds of 0.53 and $1.60 \mathrm{~m} / \mathrm{min}$ are shown in Table 2.

At the casting speed of $0.53 \mathrm{~m} / \mathrm{min}$ the absolute fluctuations of meniscus vary with the distance from the narrow face of mold. It is approximately $8 \mathrm{~mm}$ at the position $3 \mathrm{~mm}$ apart from the narrow face of mold, and the figure is about $70 \%$ of the amplitude of mold oscillation. At the casting speed of 1.60 $\mathrm{m} / \mathrm{min}$, the meniscus fluctuations are about $11 \mathrm{~mm}$, being greater than the value at $0.53 \mathrm{~m} / \mathrm{min}$. Also, at the casting speed of $0.53 \mathrm{~m} / \mathrm{min}$, the meniscus fluctuations increase as the distance from the narrow face of mold increases. Conversely, at the casting speed of $1.60 \mathrm{~m} / \mathrm{min}$, the meniscus fluctuations decrease as the distance from the narrow face of mold increases.

Figure 6(a) shows a typical relationship between the mold displacement and the absolute displacement 
of meniscus at the position $3 \mathrm{~mm}$ apart from the narrow face of mold at the casting speeds of 0.53 and $1.60 \mathrm{~m} / \mathrm{min}$ in the upward direction of mold oscillation. Figure 6(b) shows the relationship in the downward direction of mold oscillation. At the casting speed of $0.53 \mathrm{~m} / \mathrm{min}$, the meniscus is stationary regardless of the direction of mold movement. The meniscus begins to move when the mold moves about 2

Table 2. Absolute fluctuation of meniscus.

\begin{tabular}{ccc}
\hline \multirow{2}{*}{$\begin{array}{c}\text { Casting speed } \\
(\mathrm{m} / \mathrm{min})\end{array}$} & \multicolumn{2}{c}{ Absolute fluctuation of meniscus $(\mathrm{mm})$} \\
\cline { 2 - 3 } & $\begin{array}{c}3 \mathrm{~mm} \text { from } \\
\text { mold wall }\end{array}$ & $\begin{array}{c}10 \mathrm{~mm} \text { from } \\
\text { mold wall }\end{array}$ \\
\hline 0.53 & mean \pm 4.2 & mean \pm 6.2 \\
1.60 & mean \pm 5.5 & mean \pm 4.6 \\
\hline
\end{tabular}

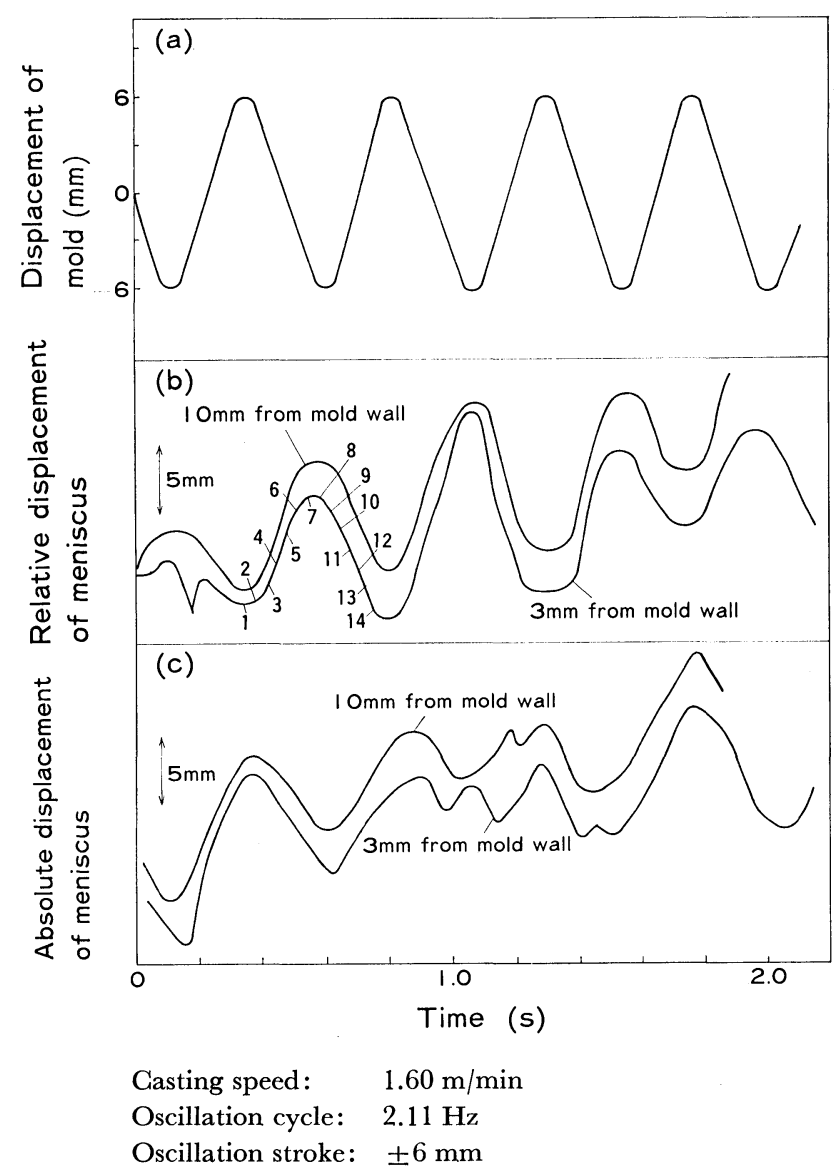

Fig. 5. Behavior of the meniscus at casting speed of $1.60 \mathrm{~m} / \mathrm{min}$. to $3 \mathrm{~mm}$ after the reversal of the direction of mold oscillation. At the casting speed of $1.60 \mathrm{~m} / \mathrm{min}$, unlike the case at the casting speed of $0.53 \mathrm{~m} / \mathrm{min}$, the meniscus begins to move immediately after the reversal of the direction of mold oscillation.

\section{Shape of Meniscus}

Figure 7 shows the change in meniscus shape at the casting speed of $0.53 \mathrm{~m} / \mathrm{min}$ with the absolute displacement of meniscus. The same one at the casting speed of $1.60 \mathrm{~m} / \mathrm{min}$ is shown in Fig. 8. It was found from Figs. 7 and 8 that the meniscus always shows a convex profile.

The meniscus profiles shown with subscripts in Figs. 7 and 8 correspond to those observed at times indicated by the same subscripts in Figs. 4 and 5 .

Figure 9 (a) shows the relationship between the mold displacement and the meniscus radius of curvature in the section $3 \mathrm{~mm}$ apart from the narrow face
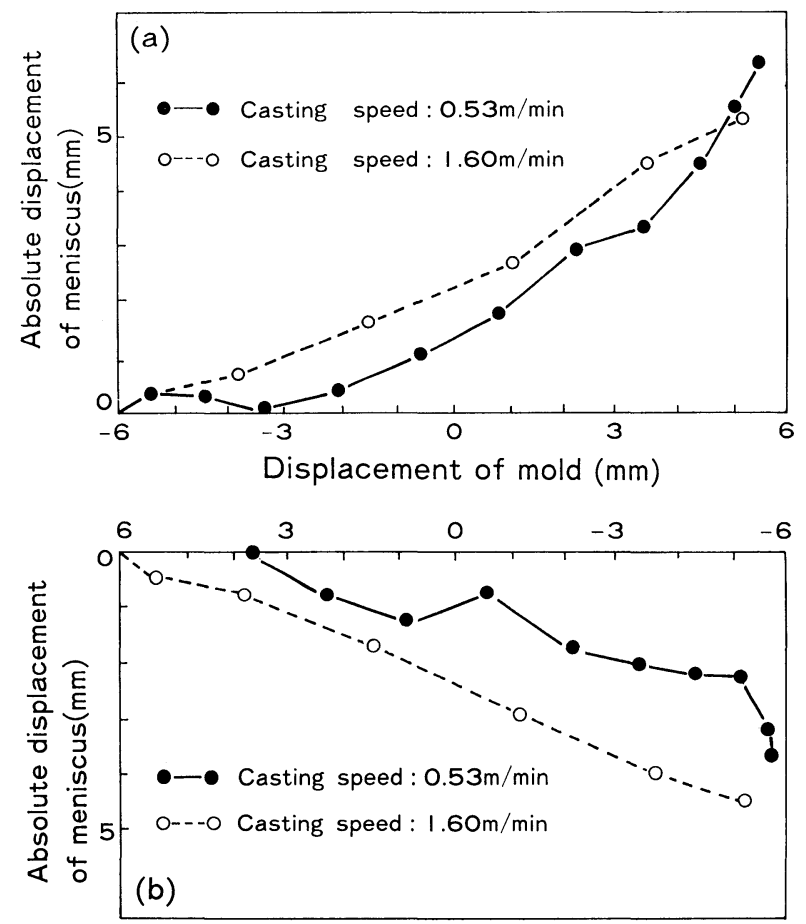

(a) Oscillation direction: up

(b) Oscillation direction: down

Fig. 6. Relationship between mold displacement and meniscus displacement.
Casting speed: $0.53 \mathrm{~m} / \mathrm{min}$

Fig. 7. Change in meniscus profile at casting speed of $0.53 \mathrm{~m} / \mathrm{min}$.

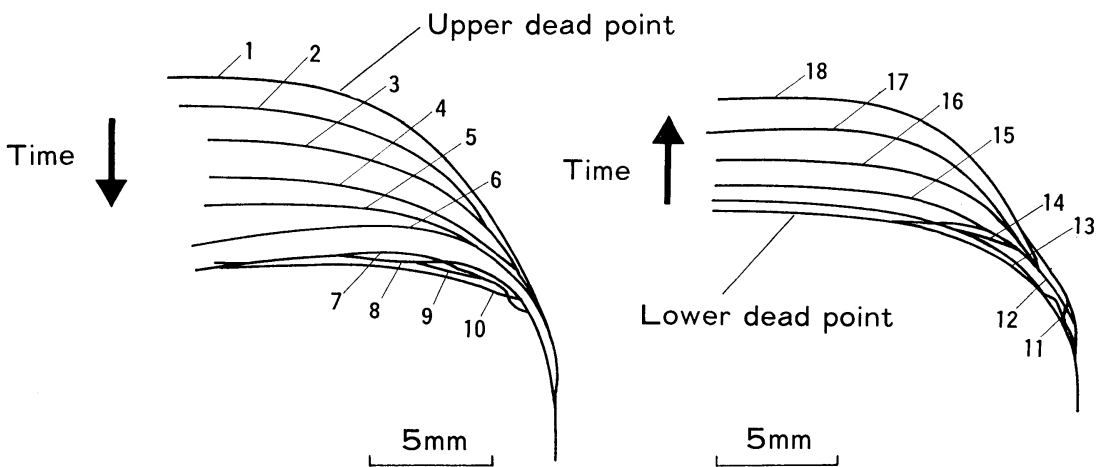

(a) Mold goes down. (b) Mold goes up. 


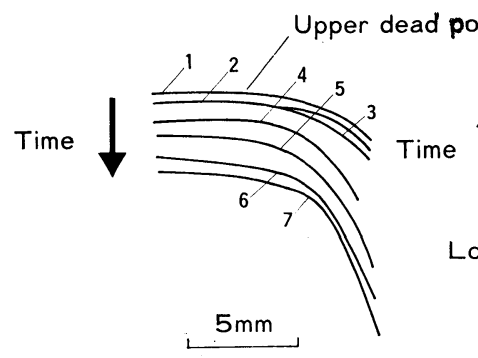

(a) Mold goes down.

Casting speed: $1.60 \mathrm{~m} / \mathrm{min}$

Fig. 8. Change in meniscus profile at casting speed of 1.60 $\mathrm{m} / \mathrm{min}$.

of mold in the upward direction of mold oscillation. Figure 9(b) shows the relationship in the downward direction of mold oscillation.

It was made confirmed that the meniscus curvature changes with the displacement of mold oscillation.

\section{Conclusion}

From the on-direct observation of the meniscus, the following findings have been obtained:

(1) The meniscus is not stationary, but fluctuates at the same period and phase as those of mold oscillation.

(2) The absolute fluctuations of meniscus are about $70 \%$ of the amplitude of mold oscillation at the position $3 \mathrm{~mm}$ apart from the narrow face of mold.

(3) The absolute fluctuations of meniscus at the position $3 \mathrm{~mm}$ apart from the narrow face of mold in high-speed casting $(1.60 \mathrm{~m} / \mathrm{min})$ are larger than those in low-speed casting $(0.53 \mathrm{~m} / \mathrm{min})$.

(4) The meniscus radius of curvature varies with the displacement of mold oscillation.

(5) The meniscus always shows a convex profile upward.

Possible causes for meniscus fluctuations synchronized with mold oscillation are:

1) Periodical deformation of the solidified shell in mold due to mold taper and mold oscillation

2) Periodical deformation of the initial solidified shell due to pressure fluctuations in the film of the molten powder

3) Fluctuations of the solidified shell due to the wetting condition of the molten powder and mold
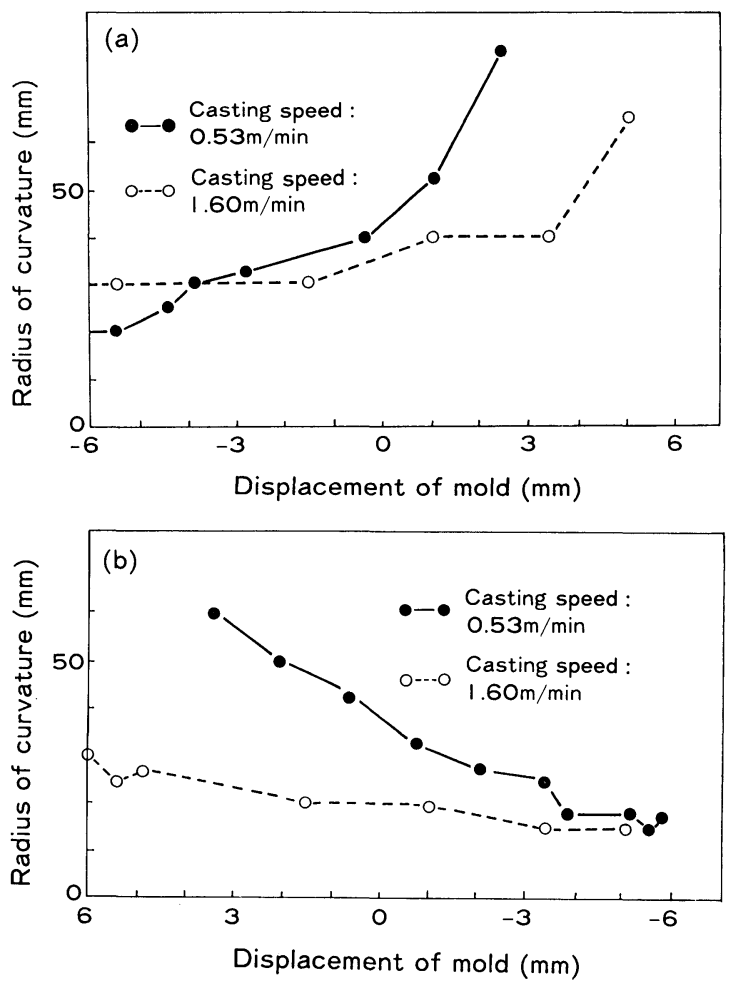

(a) Oscillation direction: up

(b) Oscillation direction: down

Fig. 9. Relationship between the mold displacement and meniscus radius of curvature.

surface.

Further investigation the contribution of each of these causes to the meniscus fluctuations should be done in the future.

From the present experiment it has been revealed that the surface wave motion of molten steel in mold is caused by mold oscillation.

\section{REFERENCES}

1) K. Suzuki, K. Murata, K. Nakanishi, M. Shinra, M. Kodama, S. Kojima and Y. Miyazaki: Tetsu-to-Hagané, (1983), S912.

2) D. K. Stemple, E. N. Zulueta and M. G. Flemings: Metall. Trans. B, 13B (1982), 503.

3) E. Takeuchi and J. K. Brimacombe: Metall. Trans. B, 15B (1984), 493. 